\title{
The Journal and 15 Years
}

\author{
Eelco F. M. Wijdicks ${ }^{1}$
}

Published online: 6 November 2017

(C) Springer Science+Business Media, LLC 2017

I want to use this parting editorial to tell the readers unreservedly what a wonderful experience I have been afforded and to introduce the new editor-in-chief. It is time to hand over the keys. I have taken the journal as far as I can. Allow me to say a few words about editorship in general, the journal's modus operandi, the current publishing reality, and future risks and opportunities. This reflection on the journal's reach and impact will expand on what I have previously said in annual editorials [1-15].

I am often asked-how do you start a journal? We started from nothing and nothing at all. After many flat-out rejections, we received support from a publisher (Humana Press) late 2002. We began in 2003 with a fresh international editorial board eager to get material for NEUROCRITICAL $C A R E$. Subsequently, I sent personal emails to hundreds of authors to solicit papers to an unindexed, unknown, and yet undefined, uncommon quarterly journal. It was a different time-now prospective authors are bombarded with requests to write for open-access journals, to submit for the inaugural issue to be published a few weeks hence, and even to join editorial boards. I hope few fall into this exploitative trap. But we were fortunate and received enthusiastic responses to write for our new journal. The manuscripts that trickled in were quite good-written to our specifications rather than dusty, previously rejected manuscripts authors had filed away. A year later, we thought we had collected enough papers to launch the journal. Fifteen years later, after 95 issues and almost 2000 articles, here we are.

Eelco F. M. Wijdicks, MD, PhD, FNCS

wijde@mayo.edu

1 Division of Critical Care Neurology, Mayo Clinic, Rochester, MN, USA
I am often asked-what do you do as editor-in-chief? It is everything they say. Being an editor is like a physician - the learning curve and the day-to-day responsibilities of running the journal can consume your private life. Undoubtedly, editing a journal such as NEUROCRITICAL $C A R E$ requires a daily commitment to stay on top of the workload. Skipping a day means the next day is busy. Skipping a week may require a whole day of catching up - often on minutiae. To some extent, it a one-person cottage industry.

And then there are the emails-many of them. Reviewers are busy, some very busy, on vacation (neurointensivists do vacation now?), "swamped," "in the unit" (indeed, we all are!) This process does offer occasions for humor-such as when a prospective reviewer recently declined but assured me that "from now on, we shall strive for good relations." What do we do with the reviewers who say yes and then do not come through even when kindly nudged? Given the changes in clinical practice (notes and more notes) and the pressures in medical and basic science (grants and more grants), it has become harder to find willing, knowledgeable reviewers. I predict this will become a high-priority concern in the near future. Perhaps reviewers need more incentive, e.g., Publons.

But how about the decision-making process? Over the years, I created my own code of conduct to define what I needed to avoid, and I tried to stick to it. At the risk of sounding presumptuous, I have listed the precepts (Table 1). However, they are non-prescriptive, and I will clarify them in this editorial. The reward for sticking to code derives from the discovery of well-written, carefully analyzed, and thoughtfully prepared submissions, especially when they describe original new observations. This reward more than compensates for papers that you know, from the opening sentence, will not make it past our 
Table 1 My Code of Conduct as Editor-in-Chief

1. Accept only unbiased papers

2. Edit but do not rewrite a paper

3. Multiple revisions do not improve a paper

4. Stick to a decision but a strong rebuttal may lead to rereview

5. Reject without straw manning

6. Accept an honest revision

7. Appreciate a good reviewer

8. Do not game the impact factor

9. Be hands on and move papers forward

10. Keep control over the production process

reviewers, and should not even be considered. Over the years many submitted papers tried to solve problems that do not exist.

Much has been written on the impact factor, which in this new rating-obsessed world seems to gain more prominence. Every journal has its niche in academia, and editors should avoid the temptation to sacrifice solid research in a ridiculous, unacademic quest for a rising impact factor. In good conscience, I could not manipulate the impact factor by soliciting brief updates packed with recent citations. Filling up the journal with citable personal opinions does not promote good scholarship. The impact factor provokes too many fireworks. Too much emphasis on metrics can collapse the main purpose of a journal-to improve practice, to invite research in unexplored areas, and to publish thought through guidelines.

How do you review papers as an editor? You can't just send them out and have reviewers decide. Too many reviewers recommend acceptance without any suggestion. Too many reviewers reject essentially good papers. Over time you learn to judge papers on their merit. An editor must recognize - by reading a lot-what is interesting and compelling for the readership and what is stale. This requires reading the full paper and suggesting modifications. On the other hand, journal editors cannot be judge, jury and executioner. I had mostly great and meticulous peer reviewers during my tenure, and they are herewith thanked again. The reviewers identified issues I greatly overlooked, some serious such as double publication, offered shrewd advice, and were there to help to improve the paper if possible. Many times I thought we should have a real dialogue, but there is no good pathway for that.

Decisions are sometimes painful, but commonly rescinding rejections leaves the editor clinging precariously to the proverbial slippery slope. I mostly answered emails and avoided typical editor behavior such as hiding behind surrogates or sending generic rejection emails to dismayed authors. To reject is part of the job, and you do a lot of it. Fortunately, most authors understand the process and accept rejection. But there were also the others: 'fuming' authors who just learned of their rejected article and could not refrain from sending a scathing rebuttal (or, later, from notifying me that the paper got published in a 'better' journal). Sometimes I relented, found the rebuttal valid, and had a paper reviewed again. Other referees often found the same flaws. But once a paper is sent out for revision, the editor should work on getting it in the best possible shape. I cannot recall rejecting a paper whose authors subjected it to a thorough revision upon recommendation of the reviewers. I could empathize with those authors and respected their willingness to put in additional effort to improve their work. Editors should not reject papers after an honest revision. I did not like it when it happened to me.

During most of my tenure, I worked with a small group of editorial assistants provided by Springer. Support for journals of this caliber is variable. In this era of outsourcing, papers go somewhere and come back only to go somewhere else before the galleys are finalized. The team behind it is generally unknown to editors. There is a clearly visible gap between editors and production, and editors must build in safeguards to prevent becoming completely alienated from the production process. Compared to paper production, digital production is very fast; with that speed, come errors, which should be an ongoing concern of editors, many of whom are academics who must still come to terms with the digital world. Many publishers have rules they cannot change. Systems break down occasionally, and often the editor is the first to call it out. Sometimes it takes every possible intervention and a fusillade of calls and emails to get it fixed. Maybe we should wait for IBM Watson to solve all our problems.

The world of publishing is changing and recalibrating. Journals are on the road to an unspecified place. I saw how quickly journals became fully handled electronically. The stacks of papers evaporated quickly, offices are now digital, and there is access to the work anywhere. I could be anywhere and had many devices to assist me (Fig. 1). I suspect the Journal will become exclusively digital only because that is how we all basically read papers. Let's admit it, we have all seen (or added to) stacks of wrapped journal issues never to be opened and waiting for the bin.

All that remains is to share a few of my personal highlights. The first was the realization that the journal was here to stay. Few know how easily journals fold and how easy it is to fall behind. I was the last one who felt we could stay afloat and could not have been more pleased when we crossed the Rubicon. It made me smile when papers published in the journal appeared on presentations in neurocritical care conferences or, more importantly, in non-neurocritical care conferences. The field of neurocritical care was relatively new academically 15 years ago-it has gained in stature since then. 
Fig. 1 Vanishing editorial office and arrival of the digital world (note the "editorial assistants")
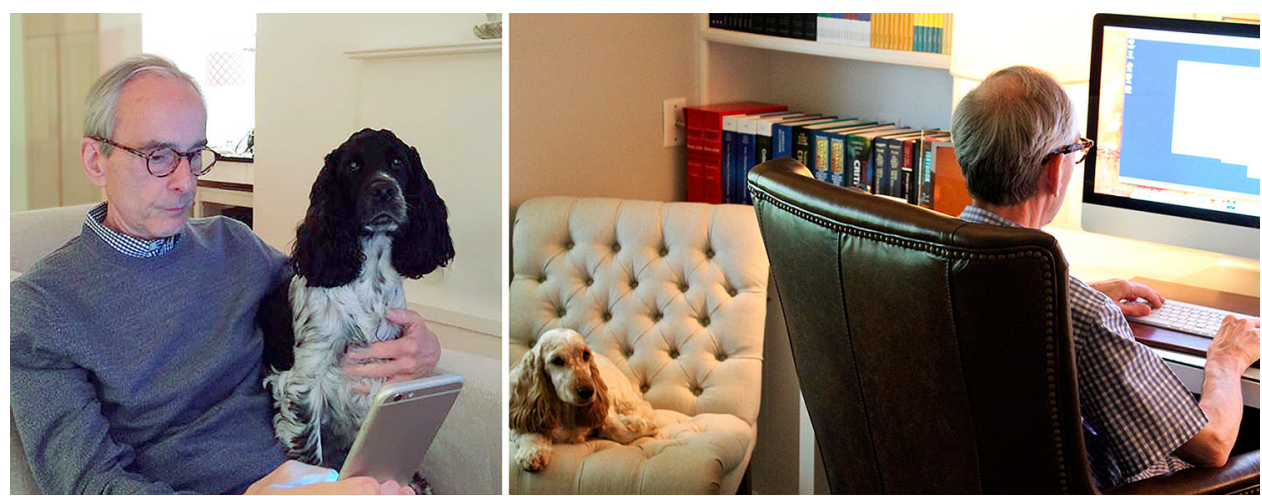

I care deeply for this journal. In many ways, the quality of a journal also requires uncompromising adherence to style. There must be a love and respect for language. I hope writers for medical journals remain creative. Journals should not be the place where literary skills go to die. Young enthusiastic writers should be allowed to find a place for their work at the journal.

In 2017 a search committee by the Neurocritical Care Society carefully vetted a successor-I recused myself from interviews. In 2018, I will step aside, and Dr Michael Diringer will take over. He has been a good friend since the early years of the specialty. He is skilled, talented, able, and a person of great integrity. He has a broad range of view, is a forceful advocate, and thoroughly knows the field. He listens hard. I hope he will agree that he has inherited a journal with good potential. I am confident he will swerve it from a predictable path and to a next phase. After 15 years (and hand-in-hand with the now 15-year-old Neurocritical Care Society), I think the readers will look back with satisfaction. I always felt that we could set ourselves apart publishing really interesting papers through careful review, avoidance of multiple revisions and editorial nitpicking, rapid decisions and copy-editing, and online posting very soon after acceptance.

Foremost, authors make a journal. More than anyone else I express my heartfelt gratitude to all the researchers who submitted their interesting work. I greatly thank the associate editors (Stephan Mayer, Gene Sung, David Warner, Michael James, Neeraj Badjatia, Alejandro Rabinstein) and editorial board for their commitment and supporting advice. I thank all the workhorses (pun intended) of Springer during my years of editorship, many overseas, many involved, and many anonymous. Divya Nagarajan for many years operated as the editorial manager. In the USA, I have appreciated the assistance of Richard Lansing, Benjamin Ellis, Jim Geronimo, Jim Langlois, and Sean Beppler over many years. I also thank the
Society-supported copy editors, Lori Lynn Reinstrom and Jesse Welsh. I thank the Neurocritical Care Society leadership for their unwavering support and encouragement over all these years.

I did not imagine my tenure would last this long, but after signing off I will be doing what I have always done. I may be bidding farewell to high-level editing but not to writing, and I hope to contribute regularly to the journal. Thank you for your trust.

\section{References}

1. Wijdicks EFM. A new journal, a new step, a new energy. Neurocrit Care. 2004;1:1.

2. Wijdicks EFM. One year past, the new assignment. Neurocrit Care. 2005;2:1-2.

3. Wijdicks EFM. Losing that novice feeling. Neurocrit Care. 2006;4:1-2.

4. Wijdicks EFM. Neurocritical care: it's what we do and what we do best. Neurocrit Care. 2006;5:81.

5. Wijdicks EFM. A good year: progress and aspirations. Neurocrit Care. 2007;6:1.

6. Wijdicks EFM. The journal and the field. Neurocrit Care. 2008;8:1-2.

7. Wijdicks EFM. Practice, politics, and papers. Neurocrit Care. 2009;10:1-3.

8. Wijdicks EFM. The duties and ethics of the journal. Neurocrit Care. 2010;12:1-3.

9. Wijdicks EFM. The journal and the rest of the world. Neurocrit Care. 2011;14:1-3.

10. Wijdicks EFM. The journal and academia. Neurocrit Care. 2012;16:1-3

11. Wijdicks EFM. The journal and originality. Neurocrit Care. 2013;18:1-4.

12. Wijdicks EFM. The journal and its first decade. Neurocrit Care. 2014;20:1-2.

13. Wijdicks EFM. The journal and priority. Neurocrit Care. 2015;22:1-2.

14. Wijdicks EFM. The journal and guidelines. Neurocrit Care. 2016;24:1-2.

15. Wijdicks EFM. The journal and social media. Neurocrit Care. 2017;26:1-2. 